\title{
The English split infinitive: A comparative study of learner corpora
}

Phoocharoensil, Supakorn

Thammasat University, Thailand(yhee143@gmail.com)

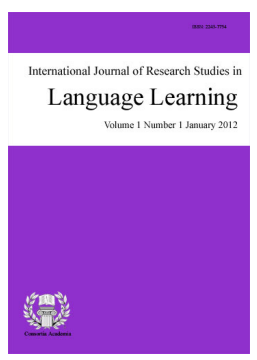

ISSN: $2243-7754$

Accepted: 15 October 2012

OPEN ACCESS

\section{Abstract}

The split infinitive in English has been controversial for over a century. Whilst a prescriptive grammar rule forbids infinitive splitting, it seems that modern grammar academics, as well as users, accept and allow for its occurrence. The approval of split-infinitive structure has also been clearly substantiated by plenty of convincing linguistic evidence: real data from native-speaker corpora confirms its existence in different varieties of English. The present study, using the data collected from Thai Learner English Corpus (TLEC), shows that professional English learners evidently produce a greater number of split infinitives than intermediate learners, whose proficiency level is lower. According to a comparative study of the two learner corpora, the higher the proficiency level of the learner, the greater of the production of the split infinitives, and low-proficiency learners seem to use split infinitives in a more specific context.

Keywords: split infinitive; learners' proficiency; learner corpora; corpus-based data; corpus linguistics 


\section{The English split infinitive: A comparative study of learner corpora}

\section{Introduction}

To split or not to split infinitives? appears to be a truly controversial issue in English linguistics (Crystal, 2003; Mikulova, 2011; Mitrasca, 2009). Native speakers of English, or even those speaking the same dialect, may be confused over whether or not it is grammatically correct to split infinitives. More and more scholars at present regard the split infinitive as a natural, well-formed construction in English (Trask, 2007). On the other hand, there has also been a group of purists adhering to a rigorous standard of accuracy, thereby disagreeing with an item, e.g. an adverb, being inserted between the infinitive marker to and the verb, as in to perfectly understand (Mitrasca, 2009). Even several educated people today are obviously sensitive about the split infinitive use, strongly criticizing and trying consciously to avoid it, particularly in writing (Crystal, 2004). Opinions on the pros and cons of the split infinitive in English are now accessible to all scholars; however, these ideas are dependent upon native speakers' differing and unique senses of intuition. This is why some researchers have begun to use corpus-based evidence to enhance their studies on the split infinitive in native-speaker English (e.g. Albakry, 2005; Carter \& McCarthy, 2006; Mikulova, 2011; Mitrasca, 2009).

Nevertheless, until recently, little attention has been given to the split infinitive in learner English. More importantly, there apparently exist few research studies focusing on the interlanguage of EFL (English as a foreign language) learners. For this reason, the present study examines the uses of split infinitives in two learner corpora of English writings by Thai EFL learners: professional learner English and intermediate learner English. With two proficiency groups of learners in its design, the research is able to compare linguistic features like split infinitives between the two groups, which then lead to a clearer picture of the interlanguage split-infinitive knowledge of Thai students (Ellis, 2008).

The concept of the English split infinitive and its history are briefly described in the next section. In addition, arguments for and against it, as well as previous relevant studies on split infinitives in the corpora of native-speaker English are reviewed.

\section{Literature review}

\subsection{The split infinitive: structure and origin}

The split infinitive refers to the structure in which a word or phrase, such as an adverb, is positioned between the infinitive marker to and the verb in the base form (Huddleston \& Pullum, 2002). While such a construction has been so far labeled as an ungrammatical usage by prescriptive grammarians, strongly believing that conventional language rules should be strictly followed, modern descriptive grammarians, focusing on language as it is actually used, accept the split infinitive as a well-formed structure (Mitrasca, 2009). The controversy surrounding the split infinitive clearly has been ongoing for more than a century (Crystal, 2003).

Although the split infinitive is often assumed to belong to modern English, especially in American English, the construction originally occurred in Middle English period of the $13^{\text {th }}$ century. Its occurrence dropped throughout the $16^{\text {th }}$ and $17^{\text {th }}$ centuries and its revival emerged by the end of the $18^{\text {th }}$ century (van de Gaaf, 1933). Despite being considered erroneous by some pedantic syntacticians, the usage of the split infinitive appears to have significantly risen from the 1940s on (Mikulova, 2011). Accordingly, as argued by Crystal (2003, p. 45), "infinitive-splitting is by no means an unnatural process in English, as prescriptivists argue and certainly not a modern phenomenon".

In terms of the internal structure, the split infinitive, as mentioned earlier, comprises the infinitive marker to 
The English split infinitive: A comparative study of learner corpora

and a splitter, followed by a verb in its base form. The splitter can generally be a single adverb, as in (1), a complex adverbial phrase as in (2), or the negative particle not as in (3) (Mikulova, 2011).

(1) ... a foreign minister with that of some of the men we send abroad nowadays, to fully appreciate the value of general information, and a true sense of personal and... . (Mikulova, 2011, p. 15)

(2) ...the states he's won, the red states, is they're not likely to all of a sudden turn blue in November... . (Mikulova, 2011, p. 31)

(3) They will give young people yet another reason to not go to church. (Mikulova, 2011, p. 28)

\subsection{Reasons to ban the split infinitive}

According to Leech, Deuchar, and Hoogenraad (2006, p. 184), "some people (especially older people who have gone through a traditional education) feel quite strongly that we should not split our infinitives". For these people, a separation of the infinitive marker to from the following verb "can be little short of a crime" (Leech et al., 2006, p. 184). A number of reasons, many of which are not scientific or realistic, abound for prohibition of the split infinitive. First of all, prescriptive grammarians devise rules "in the belief that their languages need regulating, tidying up, or protecting against change" (Swan, 2005, p. 66). These scholars take the view that the infinitive is a fixed linguistic unit. There should, for this reason, be no element inserted between to and the verb (Mitrasca, 2009).

Another classic reason for disallowing splitting the infinitive is associated with Latin. Many prescriptive English grammar rules, including no infinitive splitting, originated from an analogy with Latin grammar. As noted by Leech et al. (2006, p. 186), "The prestige of Latin was so enormous that English constructions that differed from the Latin model were disparaged". Under the influence of Latin grammar, in which no split infinitive exists, some English grammarians have tried to constitute grammar rules on the very basis of this Latin grammar, thus proscribing the split infinitive use (Bailey, 2006). Furthermore, some language users have been taught in a prescriptive, arbitrary fashion not to split the infinitive just because compliance with this traditional rule is somehow perceived to be a sign of erudition (Bailey, 2006; Mitrasca, 2009). In summary, because of the pervasive power of prescriptivism, the split infinitive has been treated by many traditional, punctilious grammarians, among whom its avoidance is preferred, as taboo (Peters, 2006, p. 775).

\subsection{Reasons to allow the split infinitive}

In spite of the aforementioned grounds supporting the do not split infinitive rule, increasingly, several arguments against the rule have appeared. Trask (2007) expressed his strong disagreement with the prescriptive notion that an English infinitive is an inseparable language unit, arguing that sequences like to get is, in actuality, not an infinitive, "nor is it a verb-form, nor is it even a grammatical unit at all. The true infinitive here is get, while to is nothing but a linking particle" (Trask, 2007, p. 230). In his view, if to get is not a linguistic unit, it should be possible for an item, such as an adverb, to be placed between to and get.

By relating this particular rule back to Latin grammar, the connection between the grammars of both languages is being arbitrarily made in order to facilitate English living up to the standards of Latin. In other words, the formation of English grammar rules based on Latin is probably inappropriate, resulting in a false analogy. As Crystal (1985) and Huddleston and Pullum (2002) remarked, an English infinitive phrase, e.g. to love, is translated into only one word amare in Latin. Therefore, it is impossible for a splitter to occur within this single Latin word, as it possibly does in English. The fact that no word or phrase can be inserted inside amare provides no strong basis for attacking the occurrence of an element, such as an adverb, between to and a verb in English.

In addition to this false analogy with Latin grammar, the split infinitive may be permitted according to 
analogies with other verb phrases. For example, now that an adverb can be grammatically positioned between an auxiliary and a main verb, as in (4), where the adverb actually is flanked by did not and the verb talk, there should be nothing wrong if an adverb is placed between to and the verb (Close, 1987).

(4) We did not actually talk to him. (Mitrasca, 2009, p. 105)

Moreover, by analogy to noun phrases such as the good man, where the adjective good comes between the definite article the and the noun man, a construction such as to really understand, where the splitter really exists in the middle of the infinitive should, by the same token, be viewed as grammatical as well (Crystal, 2003). As noted by Jesperson (1933, p. 331), the split infinitive is a misnomer "...for the preposition to no more belongs to the infinitive as a necessary part of it, than the definite article belongs to the substantive, and no one would think of calling the good man a split substantive". In a similar vein, according to Huddleston and Pullum (2002, pp. 1183-1184), to serves as an infinitive-phrase marker but is not syntactically in the construction with the verb base. Put differently, to is actually not a part of the infinitive phrase, and an occurrence of an element like an adverb between to and the infinitive should not be viewed as an error.

A close, careful observation of compound verbs in the infinitive form, e.g. to overthrow, is also indicative of split infinitive permission (Crystal, 2003; Leacock, 1944). In the above sample verb, the prefix over-seems like being added between to and throw, so is a splitter, as in to strongly throw. This may suggest that to and the following verb do not have a fixed attachment. On the contrary, they are also susceptible to splitting by a word like an adverb.

Another argument against the prohibition of the split infinitive lies in the rhythm of English. As can be seen in the very well-known phrase To boldly go where no man has gone before, at the beginning of many Star Trek television episodes and films, from 1966 onward, Crystal (2003, p. 195)'s view is that the phrase "has one big thing in its flavor. It is following the natural rhythm of English". The split infinitive is "often the most acceptable rhythmical alternative in speech" (Crystal, 2001, p. 162). This is consistent with Copperud (1964, p. 201), who maintained that a split infinitive is acceptable if it does not damage the rhythm or meaning of the sentence.

Such a concept is also in line with Marshall and McDonald (1995) in that unsplitting the infinitive, e.g. to go boldly, means a loss of the rhythmic force which the original version possesses. In a similar way, Strumpf and Douglas (2004, p. 160), even though they treat the split infinitive as a grammatical mistake, made some allowances for infinitive splitting, stating that "Some well-known writers have taken artistic license to split infinitives...to emphasize certain points or simply to create more poetic constructions".

It is also found that the split infinitive can effectively reduce vagueness or even eliminate ambiguity in English (Calle-Martin \& Miranda-Garcia, 2009, p. 361). According to Oxford online dictionaries, "avoiding a split infinitive can sound clumsy. It can also change the emphasis of what's being said". For instance, the differences in the position of the adverb really in (5) and (6) shown below leads to dissimilar meaning focuses. Whereas (5) conveys the meaning 'it is important that you watch him', (6) is understood as 'You have to watch him very closely'. If a speaker says (5), strictly conforming to the no-infinitive-splitting rule, even though the intended meaning is that of (6), it is obvious that the real meaning is not imparted to the listener. In summary, the application of split infinitive in (6) helps make the speaker's intention clearer.

(5) You really have to watch him.

(6) You have to really watch him. (http://oxforddictionaries.com/page/grammartipsplitinfinitive)

The notion in the preceding paragraph agrees with Gowers (1954)'s disapproving attitude towards the avoidance of infinitive splitting, which hampers clear writing and promotes ambiguity "by inducing writers to place adverbs in unnatural and even misleading position" (Gowers, 1954, as cited in Crystal, 2003, p. 195). It is, therefore, in certain contexts, necessary for an infinitive to be split in order to preserve intended meaning (Stageberg \& Oaks, 2000). According to Swales and Feak (2004, p. 23), even though split infinitives are not very 
common in academic writing, "they are sometimes used, particularly in order to avoid awkwardness or ambiguity". This is in line with Curme (1914, 1930), who asserted the usefulness and effectiveness of split infinitives, which have been used throughout the history of English.

Overall, it seems that the use of split infinitive is grammatically acceptable, as Marshall and Mcdonald (1995, p. 77) expressed, "[split infinitives] are not, strictly speaking, grammatically incorrect". There is no rule of grammar requiring to and the verb to be adjacent. Huddleston and Pullum (2005, p. 206) confirmed the acceptability of the split infinitive structure:

\section{Phrases like to really succeed have been in use for hundreds of years. Most usage manuals now recognize this, and also recognize that in some cases placing the adjunct between to and the verb is stylistically preferable to other orderings.}

The arguments in favor of split infinitive prohibition are relatively weak, especially when compared to the numerous reasons supporting this syntactic phenomenon. As seen in the next section, actual occurrences of the split infinitive in present-day English from native speaker corpora, i.e. real data of English use, abound.

\subsection{The split infinitive in native-speaker corpora}

A language corpus, which is defined as "a large, principled collection of naturally occurring texts (written or spoken) stored electronically" (Reppen, 2010, p. 2), is nowadays one of the tangible, reliable sources of authentic linguistic evidence. Instead of solely relying on individual native speakers' intuition as to what degree the split infinitive is really used, linguists now can search by themselves for what they want to know, from language corpora. There have been many corpus-based studies revealing the split-infinitive existence in native English speakers' language, to be discussed below.

Albakry (2005) compared the use of English features in New York Times and USA Today, indicating that, of all infinitive constructions in the two American newspapers, the split infinitive occurs approximately $6 \%$ and $10 \%$ in New York Times and USA Today respectively. This probably suggests that USA Today is more open to prescriptively inappropriate use, e.g. the split infinitive. In addition, a deeper analysis of the split infinitive found in both newspapers reveals the adverb to be the most common splitter (Albakry, 2005, p. 145). Albakry (2005, p. 146) also discovered that the typical adverbs employed are adverbs of manner, e.g. significantly, and the primary motivation for the split-infinitive use lies in a communicative need for emphasis.

In their compilation of the comprehensive grammar reference Cambridge Grammar of English, Carter and McCarthy (2006), whose linguistic data were based on the Cambridge International Corpus (CIC), composed of British English, American English, and other varieties of English, showed that split infinitives are very common in spoken English and pass unnoticed, "though they are often thought inappropriate in writing." (Carter and McCarthy, 2006, p. 596), as in "So if you'd like to perhaps continue..." (p. 596).

Mitrasca's study (2009), based on corpus-informed data, was aimed at exploring the frequency of split infinitives in British and American English. The British National Corpus (BNC) was consulted for information on split infinitive use in British English, while The Corpus of Contemporary American English (CCAE) and The Brown Academic List represented the American counterpart, supplemented by the well-known powerful search engine Google. The study shows a clear difference between British and American usages of split infinitives: Americans evidently produced split infinitives approximately three to four times more often than the British. Regarding the splitters used in both varieties, the Americans apparently employed double adverbs as splitters, e.g. at least, not only, kind of, sort of, etc., while the British rarely did so. Furthermore, the negative adverb never and the negator not occur more frequently in American English than British English.

This research project also presented an interesting finding on the occurrence of compound-adverb splitters in American English. Specifically, the adverb more is seen as the most common adverb splitter among compound 
splitters, e.g. to more fully understand, to more accurately reflect, to more closely match, etc. (Mitrasca, 2009, p. 119). With the up-to-date information from Google being taken into consideration, the obsolescence of the no-splitting-infinitive rule has become far clearer. The researcher, nonetheless, warned that the information from Google does not entirely represent native speakers' English; speakers of English as a second or third language may also be one of the sources of the split infinitives. Notwithstanding this, it perhaps confirms that the split infinitive is at present prevalent in different varieties of English.

In a recent study by Mikulova (2011), who investigated the split infinitives in the British National Corpus (BNC) and the Corpus of Contemporary American English (COCA), one distinction between British and American uses of split infinitives is notable. The split infinitives occur with higher frequency in the COCA than in the BNC, which found support for Mitrasca's findings (2009). As the data from BNC demonstrates, there is a preponderance of split infinitives in the spoken English over those in the written counterpart. The COCA data, by contrast, revealed an almost equal distribution in spoken and written genres. The focus of this study was on the splitters used in both genres and the findings showed that adverbials are the most common splitters, corroborating Albakry (2005). Table 1 shows the most frequent 16 adverb splitters in the BNC and COCA.

\section{Table 1}

The most frequent adverb splitters in BNC and COCA

\begin{tabular}{ll|ll}
\hline \multicolumn{1}{c}{ BNC } & \multicolumn{2}{c}{ COCA } \\
\hline actually & 430 & just & 3620 \\
just & 273 & really & 3405 \\
really & 217 & actually & 1992 \\
even & 149 & better & 1780 \\
further & 148 & even & 1616 \\
fully & 135 & further & 1182 \\
completely & 74 & fully & 1168 \\
always & 61 & kind of & 826 \\
finally & 54 & always & 779 \\
better & 41 & simply & 687 \\
still & 38 & also & 629 \\
correctly & 25 & still & 511 \\
seriously & 23 & accurately & 449 \\
greatly & 19 & completely & 418 \\
jointly & 19 & truly & 345 \\
boldly & 12 & seriously & 311 \\
\hline Sorce. (Mikulya
\end{tabular}

Source. (Mikulova, 2011, p. 27)

A less frequent type of splitter discovered in the study is the negator not, as in (7), also occurring more in American English than British English. In both corpora, the splitter not appeared with slightly more frequency in written English.

(7) And when - inevitably - you do not capsize, you soon learn how to not make the same mistakes again. (Mikulova, 2011, p. 28)

In (7), even though the split-infinitive use to not make and the prescriptively preferred version not to make seem to be semantically equivalent, the degree of negation is somehow different. In other words, according to Fitzmaurice (2000, p. 177), not being placed right before to probably sounds less negative than not existing between to and the verb.

Apart from simple adverbs and not as splitters, more complex adverbials, e.g. just sort of, sort of just, all of a sudden, etc., also exist in American English rather than British English. Moreover, an application of adverbial comparison beginning with more as in to more fully, to more effectively, to more closely etc., was found far more often in the American corpus rather than the British one.

All the reviewed studies show that split infinitives actually exist in native-speaker English, which supports 
Stageberg and Oaks (2000, p. 333), who claimed that despite the textbook rule against this forbidden grammatical construction, “...the split infinitive occurs in all levels and varieties of English, though more often in speech than in writing”.

\section{Methodology}

The current study explores the split infinitives in a corpus compiling Thai learners' English, referred to as Thai Learner English Corpus (TLEC), which consists of three sub-corpora, namely intermediate, advanced, and professional Thai learner English. The first two sub-corpora were collected from essays written by Thai EFL learners. The corpus of intermediate learner English was derived from writings of first-year university students from various faculties of two prestigious universities in Thailand, whereas that of advanced learners was from the essays by second-year university students majoring in English at one of the two aforementioned universities. As for the professional user corpus, the data was based on writings of Thai journalists in two well-established English newspapers, the Nation and Bangkok Post.

This research study concentrates on how professional Thai speakers, the highest level of proficiency in the corpus analyzed, produce English split infinitives, in comparison to the way intermediate learners employ this grammatical feature. The cross-sectional design as such allows an investigation of Thai learners' interlanguage development in such a way that the intermediate-proficiency group members are representatives of Thai learners who are in an early stage of L2 English acquisition, whereas those with higher proficiency from the professional group demonstrated an advanced L2-English level.

Two categories of splitter: simple adverbs and the negator not, were examined. It is worth mentioning here that the adverbs entered as keywords into the corpus were selected from the shared top-ten adverb splitters from the British National Corpus (BNC) and the Corpus of Contemporary English (COCA): actually, just, really, even, further, fully, always, better. Those existing in the first ten most frequent splitters in only one, but not the other corpus were excluded, i.e. completely, finally, and simply. The occurrences of each adverb as well as not was then counted and ranked according to frequency, before being compared with the split-infinitive use of intermediate learners. Moreover, the proportion of infinitives split by each adverb and not in comparison with that of non-split types is presented.

\subsection{Research question and hypothesis}

This study was aimed at answering the question below:

$>\quad$ How do Thai EFL learners of two different proficiency levels use English split infinitives in writing?

In response to this research question, the formulated hypothesis of the study was:

\section{Hypothesis}

$>\quad$ Split infinitives actually occur in Thai English, notably in the interlanguage of users with a high proficiency level.

\section{Findings and discussion}

Table 2 reveals a greater use of split infinitives in the writings of professional Thai speakers than in that of intermediate learners. The use of split infinitives seems to belong to very high-proficiency English learners like professional Thai speakers (100 tokens), whilst far fewer tokens of this grammatical feature appear in intermediate learners' English (28 tokens). This is presumably because learners at this level may not be confident enough to use infinitives in a different way from the norm, i.e. no infinitive splitting. In particular, far more adverb splitters occur in the professional corpus (85 tokens) than in the intermediate learner corpus (15 tokens). Nevertheless, the negator splitters in the professional corpus (15 tokens) slightly outnumber those in the corpus 
Phoocharoensil, S.

of intermediate learner English (13 tokens).

Table 2

Frequency of split infinitives in professional/intermediate learners' English

\begin{tabular}{|c|c|c|}
\hline adverb splitter & professional & intermediate \\
\hline actually & 1 & 0 \\
\hline just & 4 & 3 \\
\hline really & 2 & 1 \\
\hline even & 3 & 2 \\
\hline further & 23 & 6 \\
\hline fully & 15 & 0 \\
\hline always & 5 & 3 \\
\hline better & 32 & 0 \\
\hline TOTAL & 85 & 15 \\
\hline negator splitter & professional & intermediate \\
\hline not & 15 & 13 \\
\hline TOTAL (adverb splitter + negator splitter) & 100 & 28 \\
\hline
\end{tabular}

Table 3

Ranking orders of frequency of split infinitives in professional/intermediate Thai learners' English

\begin{tabular}{|c|c|c|c|}
\hline adverb splitter rank & professional & adverb splitter rank & intermediate \\
\hline 1. better & 32 & 1. further & 6 \\
\hline 2. further & 23 & 2 .just & 3 \\
\hline 3. fully & 15 & 3. always & 3 \\
\hline 4. always & 5 & 4. even & 2 \\
\hline 5. just & 4 & 5. really & 1 \\
\hline 6. even & 3 & 6. fully & 0 \\
\hline 7. really & 2 & 7. better & 0 \\
\hline 8. actually & 1 & 8. actually & 0 \\
\hline TOTAL & 85 & TOTAL & 16 \\
\hline negator splitter rank & professional & negator splitter rank & intermediate \\
\hline not & 15 & not & 13 \\
\hline TOTAL (adverb splitter + negator splitter) & 100 & & 28 \\
\hline
\end{tabular}

From Table 3, the first three most frequent adverb splitters occurring in the professional Thai user corpus are better (32 $)$, further (23), and fully (15) respectively, compared with further (7), just (3) and always (3) noticed in the corpus of intermediate learners. It is worth noting that while the professional users produced the splitter better with the highest frequency, as in (8)-(10), not any single use of this particular adverb was spotted in the intermediate learner English.

(8) would possibly see their shipments delayed. Businesses have to better address risks for the time being," he said.

(9) so been renovating 80 in-store ad screens in both complexes to better attract advertising agencies. They will promote store active...

(10) who can accept higher risk. Offshore investment allows them to better balance their portfolios and gain the opportunity to profit...

In addition, the adverb splitter further, which occurred very frequently in both sub-corpora, seems to be used in different manners. That is, the professional Thai speakers apparently produced this adverb splitter in a variety of contexts and genres, as can be seen in (11)-(12) below. The most common verbs to follow the infinitive marker to are develop (5 tokens) and increase (4 tokens) respectively.

\footnotetext{
1 Number of tokens
} 
(11) all need to turn and focus on the problems, not do anything to further increase the risk to our country's future.

(12) He said the SEC needed to further inspect feeder funds, FIFs that have investments

In contrast to the professional writers, the intermediate learners appeared to have used the splitter further in a limited way, such as in the context of education. For example, they were also found to use further only with the verb study, as in (13)-(14).

(13) I receives bad many news are from my mother get back to further study at location Lop Buri school.

(14) The admission is test for nationwide student in order to further study in university.

This study also discovered the adverb fully employed as a splitter as often as 15 times in the professional user English, contrary to zero token in the intermediate learner English. More interestingly, many of the occurrences (10 tokens) pertain to financial and business matters, as in (15)-(17).

(15) profit for the quarter, even after increasing provisions to fully cover its $\$ 160$ million investments

(16) Mr. Prasert predicted that even if the government decided to fully float LPG prices to reflect the world market price

(17) in the US housing sector, could take three or four years to fully shake out.

Considering the use of not as a splitter, the professional learner corpus and the intermediate learner corpus yielded a very close number of occurrences: 15 tokens: 13 tokens. (18)-(25) are examples of the splitter not taken from the professional English.

(18) Siriyakorn reveals her goal in life has become clear: to not be born again.

(19) people is to prepare a script before one meets them and to not be shy about using it.

(20) not be a victim, says Mr. DeSomer. For example, it's smart to not display wealth on one's body, car or home.

(21) "I felt relaxed," said Somjit. "I think he only fought to not lose by a huge margin."

(22) more depth out of her performance as the character, and to not make it presentational as she has done

(23) the company's 10KW fuel cell could be used to not only drive the car but also to generate electricity

(24) that is left on the foam with the decorative leaves so as to not show the foam.

Using the extracts from the corpus-based samples, we may conclude that to not as a splitter occurs in several grammatical environments. In (18), the split infinitive appears as an independent unit after a semi-colon, while it is a complement of $i s$ in (19). The split-infinitive phrase in (20) follows an adjective like smart, whereas in (21) it emerges right after the control verb fought. As for (22), the infinitive phrase probably acts as a subject since it begins a clause and follows a coordinating conjunction and. The infinitive phrases in (23)-(24) show purposes. That is, the infinitive phrase in (23) informs readers of the purpose for which something is used; furthermore, to not in this split-infinitive structure is a part of the correlative conjunction not only... but also... Likewise, in (24), to not is a component of the common purpose-denoting fixed phrase so as to. 
Unlike the professional learner corpus, where the splitter to not exists in different grammatical contexts, the intermediate learner corpus indicates the use of the negator splitter mostly occurring with a preceding control verb (10 out of 13 tokens), e.g. wanted and taught in (25)-(26) respectively.

(25) I did it because I wanted to not because I had to.

\section{(26) This incident taught me to not worry before things happened}

In addition to the above particular use, the intermediate learners were also found to produce the negator splitter with the modal have to (2 tokens), as in (27). Finally, they used to not as a part of the chunk in order to, as in (28).

(27) when he has problems, etc. not only these example they have to not despise their friends,

(28) the children will get up early in the morning in order to not miss their favorite cartoons.

The findings seem to indicate that high-proficiency EFL learners employ more split infinitives than do low-proficiency ones. A review of English secondary-school and university curricula in Thailand has shown no explicit lesson on English split infinitives (Wiriyachitra, 2002). This may explain why those with low proficiency, who have limited exposure to authentic target language, were found to use this unusual grammatical structure with lower frequency, while high-proficiency learners are supposed to have seen its appearances from various sources, gaining more confidence to produce more split infinitives.

\subsection{Pedagogical perspectives of the split infinitive}

Many English teachers at this point may want to ask questions like Should we teach split infinitives to EFL students? If so, in which way should we introduce it to students? In my opinion, EFL students have a right to be aware of what the split infinitive is. We are supposed to include it in our infinitive lesson(s), perhaps incorporating authentic corpus-based data of split infinitive use in teaching materials, e.g. passages, dialogues, etc. This will help improve students' receptive knowledge of the English infinitive when they are asked to identify split infinitives found in the passages they read. Then they can also sharpen their productive skills by learning how to split the infinitive; however, this should only be a supplementary exercise, after the one in which they are required to form an ordinary infinitive structure.

It is vital as well those teachers provide students with the fact that there is nothing wrong to split an infinitive. Even native English speakers do split it, especially in spoken language (Carter \& McCarthy, 2006); globally-accepted standardized tests, e.g. TOEFL, SAT, GMAT, allow split infinitives (Mitrasca, 2009). Nonetheless, my view is that split infinitives may and should be used only on the condition that its avoidance can make the message to be communicated ambiguous or obscure. As explained earlier, the split infinitive is capable of disambiguation (Calle-Martin \& Miranda-Garcia, 2009; Gowers, 1954). Moreover, the split infinitive is obviously permissible provided that writers' purpose is to add more attractiveness and excitement to their language, such as in the Star Trek blurb, previously discussed (Copperud, 1964; Crystal, 2003).

Nevertheless, students should bear in mind that where there is no necessity for ambiguity prevention or reader captivation, such as in an official context, they are advised to constitute a conventional infinitive construction, which has been so far acknowledged as standard and pure by several people, as opposed to the split version, which is still considered as a deviation from the norm by a certain group of people, e.g. prescriptive grammarians (Trask, 2007). Learners really never know who their audience could be. If they are using split infinitives in a letter of job application, and unfortunately the reader, i.e. a potential boss, does not approve of such an infinitive use, they may run a risk of upsetting the audience, and probably end up being rejected. It is also worth mentioning here that even many universities in English-speaking countries, such as Canada, enforce the rule of split-infinitive proscription, at least at the department level (Mitrasca, 2009). Accordingly, to play safe, it is of paramount importance that English learners observe readers' preference for splitting or not splitting and 
conform to such a tradition for their bright future in education (Swales \& Feak, 2004, p. 23).

\section{Conclusion}

To sum up, the corpus data from the two sub-corpora evidently imply a significantly increased use of split infinitives as the learners' English proficiency rises. Not only do high-proficiency learners, such as the professional English users, employ more split infinitives than intermediate learners, but they also use more diverse construction as can be seen in the negator splitter occurrences within their usages. Such real use of split infinitives in the learner corpora presented in the current study, as well as in native-speaker corpora (e.g. Albakry, 2005; Calle-Martin \& Miranda-Garcia, 2009; Carter \& McCarthy, 2006; Mikulova, 2011; Mitrasca, 2009; Stageberg \& Oaks, 2000), may suggest that a condemnation of infinitive splitting is an outdated English grammar rule. Although the split infinitive largely occurs in spoken English, there is likelihood that it will be used and accepted more widely in written English in almost all varieties of English (Stageberg \& Oaks, 2000, p. $333)$.

In reality, the split infinitive is legitimate for English users. The rigidity of the rule stipulated by prescriptivists needs to be mitigated to a great extent today on account of the fact that the regulation as such is badly misleading, as proposed by Trask (2007, p. 230):

the prescriptivists' position is ignorant and wrong-headed: it represents an attempt to replace normal and elegant usage by something which is silly, unnatural and hard to understand, and which is used by nobody except some prescriptivists and those few who take them seriously.

It is, furthermore, very difficult to find any authority in linguistics to outright and always condemn the split infinitive; "...there is no logical reason not to split an infinitive" (Bryson, 1990, p. 35). The split infinitive, in actual practice, is quite common (Cowan, 2008; Leech et al., 2006, p. 184). A few people nowadays consider it grammatically incorrect, but in fact it has become common usage, and there is no need to avoid this construction (Eastwood. 2005, p. 135).

\section{References:}

Albakry, M. A. (2005). Style in American newspaper language: Use and usage. Unpublished Doctoral dissertation, Northern Arizona University.

Bailey, R. (2006). Talking about words. Split infinitives. In Michigan Today News-e. Retrieved on July 17, 2011 from http://www.umich.edu/NewsE/06_06/words.html

Bryson, B. (1990). Mother tongue. London: Penguin Books.

Calle-Martin, J., \& Miranda-Garcia, A. (2009). On the use of split infinitives in English. In A. Renouf \& A. Kehoe (Eds.), Corpus linguistics: Refinements and reassessments (pp. 347-364). NY: Rodopi.

Carter, R. \& McCarthy, M. (2006). Cambridge grammar of English. Cambridge: Cambridge University Press.

Close, R. A. (1987). Notes on the split infinitive. Journal of English Linguistics, 20, 217-229. http://dx.doi.org/10.1177/007542428702000206

Copperud, R. H. (1964). A dictionary of usage and style: The reference guide for professional writers, reporters, editors, teachers and students. New York: Hawthorn Books.

Cowan, R. (2008). The teacher's grammar of English. Cambridge: Cambridge University Press.

Crystal, D. (1985). A case of the split infinitives. English Today, 3, 16-17. http://dx.doi.org/10.1017/S026607840000119X

Crystal, D. (2001). A dictionary of language. Chicago: The University of Chicago Press.

Crystal, D. (2003). The Cambridge encyclopedia of the English language. Cambridge: Cambridge University Press.

Crystal, D. (2004). Rediscover grammar. Essex: Pearson Education.

Curme, G. O. (1914). Origin and force of the split-infinitive. Modern Language Notes, 29(2), 41-45. 
http://dx.doi.org/10.2307/2917013

Curme, G. O. (1930). Syntax. Volume III of a grammar of the English language. Boston: D. C. Heath.

Eastwood, J. (2005). Oxford learner's grammar. Oxford: Oxford University Press.

Ellis, R. (2008). The study of second language acquisition. Oxford: Oxford University Press.

Fitzmaurice, S. (2000). Remarks on the de-grammaticalization of infinitival to in present-day American English. In O. Fischer \& D. Stein (Eds.), Pathways of change: Grammaticalization processes in older English (pp. 171-186). Amsterdam: John Benjamins.

Gaaf, W. van der (1933). The split infinitive in Middle English. English Studies, 15, 15-20. http://dx.doi.org/10.1080/00138383308596605

Gowers, E. (1954). The complete plain words. London: HMSO.

Huddleston, R. D., \& Pullum, G. K. (2002). The Cambridge grammar of the English language. Cambridge: Cambridge University Press.

Huddleston, R. D., \& Pullum, G. K. (2005). A student's introduction to English grammar. Cambridge: Cambridge University Press. http://dx.doi.org/10.1017/CBO9780511815515

Jesperson, O. (1933). Essentials of English grammar. London: Allen and Unwin.

Leacock, S. (1944). How to write. London: Bodley Head.

Leech, G., Deuchar, M., \& Hoogenraad, R. (2006). English grammar for today. New York: Palgrave Macmillan.

Marshall, J., \& Mcdonald, F. (1995). Questions of English. Oxford: Oxford University Press.

Mikulova, H. (2011). Split infinitive: Corpus analysis. Unpublished Masteral thesis, Palacký University in Olomouc.

Mitrasca, M. (2009). The split infinitive in electronic corpora: Should there be a rule? Concordia Working Papers in Applied Linguistics, 2, 99-131.

Peters, P. (2006). English usage: Prescription and description. In B. Aarts \& A. McMahon (Eds.), The handbook of English linguistics (pp. 759-780). Oxford: Blackwell. http://dx.doi.org/10.1002/9780470753002.ch32

Reppen, R. (2010). Using corpora in the language classroom. Cambridge: Cambridge University Press.

Stageberg, N. C., \& Oaks, D. D. (2000). An introductory English grammar. Fort Worth: Harcourt College Publishers.

Strumpf, M., \& Douglas, A. (2004). The grammar bible. New York: Owl Books.

Swales, J. M., \& Feak, C. B. (2004). Academic writing for graduate students. Michigan: The University of Michigan Press.

Swan, M. (2005). Grammar. Oxford: Oxford University Press.

Trask, R. L. (2007). Language and linguistics. The key concepts. Abingdon: Routledge.

Wiriyachitra, A. (2002). English language teaching and learning in Thailand in the decade. Thai TESOL Focus, 15(1), 4-9. 